\title{
05 HOW SHARING STORIES CAN IMPROVE SERVICE COORDINATION TO PROVIDE OPTIMAL CARE
}

J Hawke ${ }^{1}{ }^{1}$ Gippsland \& East Gippsland Aboriginal Co-Operative Ltd

10.1136/bmjspcare-2012-000250.5

It is twelve months since the development of an "Information sharing tool" for use within the Aboriginal Community. There has been an increase in service coordination and the use of services for those with Dementia, those requiring palliative care and other services to remain living in their community. Research has shown that a record of a client's life story (including medical, family, career, likes/dislikes information) is beneficial for staff to provide culturally appropriate care and conversation. Medical Officers are now contacting the Aboriginal Community Controlled Organisation (ACCO) to request the booklet be completed with their Aboriginal clients. This has increased the relationships between the Aboriginal Community Controlled Organisation staff and mainstream Organisations that provide palliative care services to the clients. Aboriginal clients tend to go directly to the ACCO for support in the first instance. In most cases the ACCO staff has the trust and relationship with the client that the mainstream service may have not had time to establish. Studies have shown that conversations and a trusted relationship are key to providing optimal care. Whilst the booklet was 


\section{Abstracts}

first established to ensure a person's life history was not lost, when diagnosed with dementia, it is now being recognised as a useful tool to engage with clients to increase the uptake of services and to ensure the appropriate care is offered and received. 